\title{
Can Pedicle Screws be Tested During Minimally Invasive Lumbosacral Fixation?
}

\author{
Yunfen $\mathrm{Wu}^{1 *}$, Alfonso Vázquez Barquero ${ }^{1,2}$ and Dhiraj R Jeyanandarajan ${ }^{3}$ \\ ${ }^{1}$ Department of Science of Health, University of Cantabria, Spain
}

${ }^{2}$ Department of Neurosurgery, Marqués de Valdecilla University Hospital, Spain

${ }^{3}$ Department of Intraoperative Neurophysiological Monitoring, Quantum Neuromonitoring, USA

Received: 制 August 09, 2018; Published: 䟧 August 16, 2018

*Corresponding author: Yunfen Wu, Department of Intraoperative Neurophysiology, University of Cantabria, Spain

Abstract

Background: Stimulus evoked electromyography (EMG) is commonly used to identify clinically relevant misplaced pedicle screws in the lumbosacral spine. This monitoring modality is more meaningful in minimally invasive surgery. In minimally invasive surgery, the pedicle screws are usually not tested, only the pedicle access needle and the tapscrew are tested by using the same stimulation threshold. No studies have compared the electrical resistance of cannulated pedicle screws and tapscrews. This study is designed to measure and to compare the resistance of cannulated tapscrews and noncoated pedicle screws of similar electroconductive characteristics and of different diameters to determine whether the same stimulation threshold can be applied for tapscrews and pedicles screws in minimally invasive lumbosacral fixation.

Materials and Methods: Resistance measurements were obtained three times across the shank from a random sampling of nine commonly used cannulated titanium noncoated pedicle screws and nine cannulated tapscrews (three composed of titanium and six of stainless steel), one of each diameter.

Results: Resistance of all tested pedicle screws ranged from $0.1 \mathrm{ohms}$ to $0.3 \mathrm{ohms}$ and tapscrews ranged from $0.1 \mathrm{ohms}$ to $0.3 \mathrm{ohms}$. No significant differences in resistance values were observed between the cannulated noncoated titanium pedicle screws and, titanium and stainless steel tapscrews of different diameters $(\mathrm{P}>0.05)$.

Conclusion: Using non-metallic dilators, the authors propose the same stimulation threshold can be used for the testing of the cannulated tapscrew and noncoated pedicle screw of similar electroconductive characteristics to optimize the accuracy of the stimulus-evoked EMG.

Keywords: Electrical Resistance; Electromyography; Pedicle Screw; Tapscrew; Thresholds; Minimally Invasive; Lumbar Fixation

\section{Introduction}

Transpedicular instrumentation provides a high biomechanical stability for the stabilization and correction of the lumbosacral spine. Minimally invasive transpedicular placement of screws carries substantial risks due to the intimate anatomical relationship between the pedicle and the adjacent neural elements; in addition to the lack of a direct visualization of the anatomical landmarks. A variety of assistive techniques have been developed to detect pedicle wall violation and prevent neurological injury related to pedicle screw misplacement[1]. Stimulus-evoked electromyographic (EMG) has then become in an important monitoring method that helps in detecting clinically meaningful malpositioned pedicle screws that are unidentified by imaging techniques. The required intensity of a single pulse of current to activate a spinal nerve root for eliciting a constant and minimal compound muscle action potential (CMAP) is defined as the threshold. The cortical bone of the pedicle behaves as an insulant by having a high resistivity to electrical current flow. Theoretically, applying stimulus-evoked
EMG, a low intensity of current pulse passed through the implant or/and intervening pedicle cortex to cause depolarization of a nearby nerve root, and consequently eliciting a CMAP may suggest pedicle screw malposition (such as a potential pedicle fracture, canal breach, or foraminal encroachment, etc.) based on a less resistance. Stimulus-evoked EMG provides an immediate feedback of an inappropriate hardware position.

In minimally invasive surgery, after a proper pilot trajectory created by the pedicle access needle is confirmed by imaging and a proper threshold, testing or persistent stimulation of the tapscrew and the pedicle screw provides additional benefit due to their larger intraosseous extension as compared to the pedicle access needle. Nevertheless, in publications on minimally invasive surgery, the pedicle screws are usually not tested, only the pedicle access needle and the tapscrews are tested by using a same stimulation threshold[2-4]. Using non-metallic dilators, the authors hypothesize both tapscrew and pedicle screw can be tested. This study aimed to 
measure the resistance values of noncoated cannulated tapscrew and pedicle screw of similar electroconductive characteristics and of different diameters to determine if the same stimulation threshold can be applied for the testing of cannulated tapscrews and pedicle screws in minimally invasive surgery.

\section{Methods}

Nine cannulated titanium noncoated pedicle screws and nine cannulated tapscrews (three composed of titanium and six of stainless steel), one of each diameter were tested. Resistance measurements were obtained by placing two alligator clips (for a steady contact pressure between the implant and electrode) over the screw and the tapscrew shank with a commercially available digital multimeter (Fluke multimeter, Model 115; Fluke Manufacturing). Each pedicle screw and tapscrew was tested three times to minimize an intra observer error. Between each screw measurement, the multimeter was zeroed (Figures 1,2).

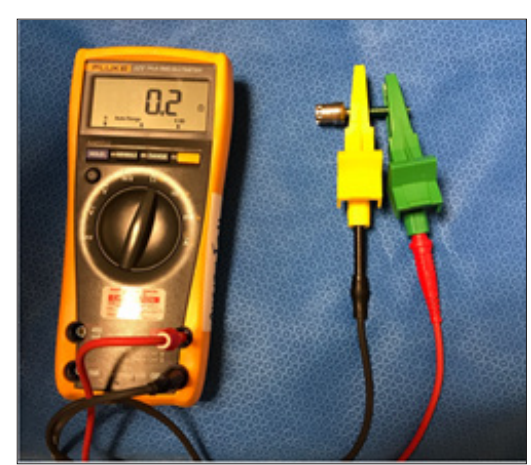

Figure 1: Measurement of the electrical resistance of a pedicle screw.

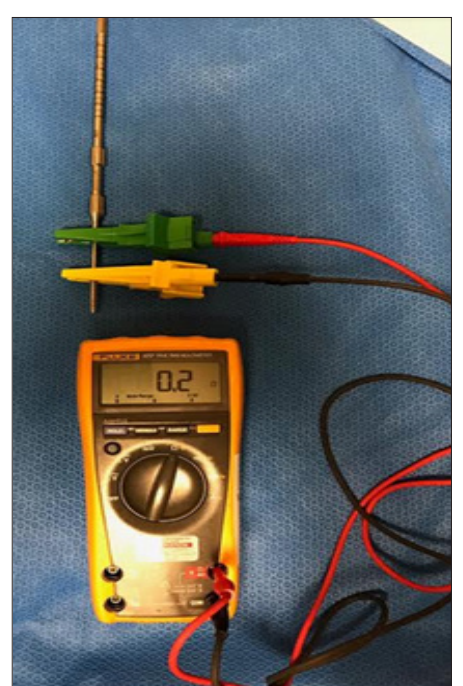

Figure 2: Measurement of the electrical resistance of a tapscrew.

\section{Statistical Analysis}

ANOVA statistical analysis was performed to assess the difference in resistance values at pedicle screws and tapscrews of different diameters. All test results were considered significant if $\mathrm{P}<0.05$.

\section{Results}

The resistance values for all the tested screws were of range of 0.1 to $0.3 \mathrm{ohms}$. Resistance of tested tapscrew ranged from 0.1 to $0.3 \mathrm{ohms}$. No significant difference in resistance values was observed between the pedicle screws and tapscrews of different diameters $(\mathrm{P}>0.05)$. The resistance values for each group of pedicle screws and tapscrews are summarized in Table1.

Table 1: Measured resistance data for cannulated noncoated pedicle screws and cannulated tapscrews.

\begin{tabular}{|c|c|c|c|}
\hline $\begin{array}{l}\text { Manufacture A Stryker ES2 } ® \\
\text { Titanium pedicle screws }\end{array}$ & $5.5 \mathrm{~mm}$ & $6.5 \mathrm{~mm}$ & $7.5 \mathrm{~mm}$ \\
\hline Trial 1 & 0.2 & 0.2 & 0.1 \\
\hline Trial 2 & 0.1 & 0.1 & 0.2 \\
\hline Trial 3 & 0.3 & 0.2 & 0.2 \\
\hline $\begin{array}{c}\text { Manufacture A Stryker ES2 } ® \\
\text { Titanium Tapscrews }\end{array}$ & $5.5 \mathrm{~mm}$ & $6.5 \mathrm{~mm}$ & $7.5 \mathrm{~mm}$ \\
\hline Trial 1 & 0.1 & 0.2 & 0.2 \\
\hline Trial 2 & 0.3 & 0.1 & 0.2 \\
\hline Trial 3 & 0.2 & 0.2 & 0.2 \\
\hline $\begin{array}{l}\text { Manufacture B K2M EVEREST } ® \\
\text { Titanium pedicle screws }\end{array}$ & $5.5 \mathrm{~mm}$ & $6.5 \mathrm{~mm}$ & $7.5 \mathrm{~mm}$ \\
\hline Trial 1 & 0.1 & 0.2 & 0.2 \\
\hline Trial 2 & 0.2 & 0.1 & 0.2 \\
\hline Trial 3 & 0.2 & 0.2 & 0.2 \\
\hline $\begin{array}{l}\text { Manufacture B K2M EVEREST } ® \\
\text { Stainless steel Tapscrews }\end{array}$ & $5.5 \mathrm{~mm}$ & $6.5 \mathrm{~mm}$ & $7.5 \mathrm{~mm}$ \\
\hline Trial 1 & 0.2 & 0.1 & 0.2 \\
\hline Trial 2 & 0.1 & 0.1 & 0.1 \\
\hline Trial 3 & 0.2 & 0.2 & 0.3 \\
\hline $\begin{array}{l}\text { Manufacture C Globus CREO MIS } ® \\
\text { Titaniumpedicle screws }\end{array}$ & $5.5 \mathrm{~mm}$ & $6.5 \mathrm{~mm}$ & $7.5 \mathrm{~mm}$ \\
\hline Trial 1 & 0.1 & 0.2 & 0.2 \\
\hline Trial 2 & 0.2 & 0.1 & 0.1 \\
\hline Trial 3 & 0.1 & 0.2 & 0.1 \\
\hline $\begin{array}{l}\text { Manufacture C Globus CREO MIS }{ }^{\circledR} \\
\text { Stainless steel tapscrews }\end{array}$ & $5.5 \mathrm{~mm}$ & $6.5 \mathrm{~mm}$ & $7.5 \mathrm{~mm}$ \\
\hline Trial 1 & 0.1 & 0.2 & 0.2 \\
\hline Trial 2 & 0.2 & 0.2 & 0.1 \\
\hline Trial 3 & 0.3 & 0.2 & 0.1 \\
\hline
\end{tabular}

\section{Discussion}

Stimulus-evoke EMG is widely used as a monitoring technique during insertion of pedicle screws in the spine. There is more consensus about the methodology including alarm thresholds on stimulus-evoked EMG for an acceptable transpedicular placement of screws in lumbosacral spinal fixation surgery. Stimulus-evoked EMG has a greater significance in minimally invasive surgery for prevention of clinically relevant pedicle wall violation [1-3]. Unrecognized screw misplacement can lead to postoperative pain, paresthesia's and paralysis. Stimulus-evoked EMG adapted to continuously electrified instruments provide immediate neurophysiological feedback and warning of suboptimal trajectories 
of the spinal instrumentation devices, minimizing neural injury and long term neurological complications [4]. Nevertheless, in contrast to open surgery, stimulation of the pedicle screw is uncommon in minimally invasive surgery $[2,3,5]$ due to instrument system electrical isolation limitation. The inserted screws are usually bigger than the tapscrews, testing of the pedicle screws provides additional benefit. To our knowledge, this is the first study intending to assess the difference in resistance values among the cannulated tapscrews and pedicle screw stimulation of similar electroconductive characteristics and of different diameters, with the aim to determine whether the same threshold can be applied for stimulation of the tapscrew and the noncoated pedicle screw.

In minimally invasive surgery, most commonly used cannulated tapscrews are fabricated with stainless steel and titanium. Hollow pedicle screws are mostly used. Titanium pedicle screws are currently the most common inserted for lumbosacral spinal fixation. Titanium and stainless steel screws have been demonstrated to have similar resistance values [6]. On the other hand, coated implants have high resistance that may interfere with modern intraoperative monitoring equipment by impeding current delivery for implant stimulation [7]. Previous studies have reported the screw shank as a reliable location for the resistance assessment[6]. In addition, the shank of the tapscrew is a common location for testing intraoperatively. In the present study, resistance values were obtained by measurement across the shank of the screws and the tapscrews. The tested cannulated noncoated pedicle screws composed of titanium, and the tapscrews composed of stainless steel and titanium (similar conductive characteristics) in this study demonstrated an insignificant difference in resistance value regarding their diameters, and among pedicle screws and tapscrews. Constant current stimulation remains the most commonly used type of stimulation on stimulus-evoked EMG monitoring. In the present study, the low levels of resistance values of the tested cannulated noncoated pedicle screws and tapscrews are not clinically significant due to most constant-current stimulators are able to deliver acceptable current flow for clinical accuracy up to a circuit resistance of at least $1000 \mathrm{ohms}$ [6].

\section{ISSN: 2574-1241}

DOI: 10.26717/BJSTR.2018.08.001596

Yunfen Wu. Biomed J Sci \& Tech Res

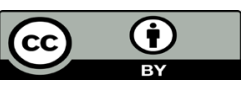

This work is licensed under Creative Commons Attribution 4.0 License

Submission Link: https://biomedres.us/submit-manuscript.php
Stimulus-evoked EMG is a valuable and reliable monitoring modality when the tested tapscrews and pedicle screws are of similar and consistent electroconductive characteristics. On the basis of our data, with use of non-metallic dilators, we would further propose the same alarm threshold can be used during tapping and the noncoated pedicle screw placement in minimally invasive lumbosacral fixation surgery.

\section{Conclusion}

Using non-metallic dilators, during minimally invasive lumbosacral fixation surgery, the authors propose pedicle screws can also be tested. Moreover, the same stimulation threshold can be used for the testing of the cannulated tapscrews and noncoated pedicle screws to further optimize the accuracy of the stimulusevoked EMG.

\section{References}

1. Wu Y, Vázquez-Barquero A (2017) Stimulus-Evoked Electromyographic Monitoring During Minimally Invasive Transpedicular Implantation of Screws in Lumbosacral Spine: Threshold Value, Methodology and Clinical Effectiveness. World Neurosurg 98: 146-151.

2. Ozgur BM, Berta S, Khiatani V, Taylor WR (2006) Automated intraoperative EMG testing during percutaneous pedicle screw placement. Spine J 6(6): 708-713.

3. Bindal RK, Ghosh S (2007) Intraoperative electromyography monitoring in minimally invasive transforaminal lumbar interbody fusion. J Neurosurg Spine 6(2): 126-132.

4. Welch WC, Rose RD, Balzer JR, Jacobs GB (1997) Evaluation with evoked and spontaneous electromyography during lumbar instrumentation: a prospective study. J Neurosurg 87(3): 397-402.

5. Wang MY, Pineiro G, Mummaneni PV (2010) Stimulus-evoked electromyography testing of percutaneous pedicle screws for the detection of pedicle breaches: A clinical study of 409 screws in 93 patients. J Neurosurg Spine 13(5): 600-605.

6. Anderson DG, Wierzbowski LR, Schwartz DM, Hilibrand AS, Vaccaro AR, et al. (2002) Pedicle screws with high electrical resistance: A potential source of error with stimulus-evoked EMG. Spine 27(14): 1577-1581.

7. Davis TT, Tadlock S, Bernbeck J, Fung DA, Molinares DM (2014) Can triggered electromyography be used to evaluate pedicle screw placement in hydroxyapatite-coated screws: An electrical examination. J Clin Neurophysiol 31(2): 138-142.

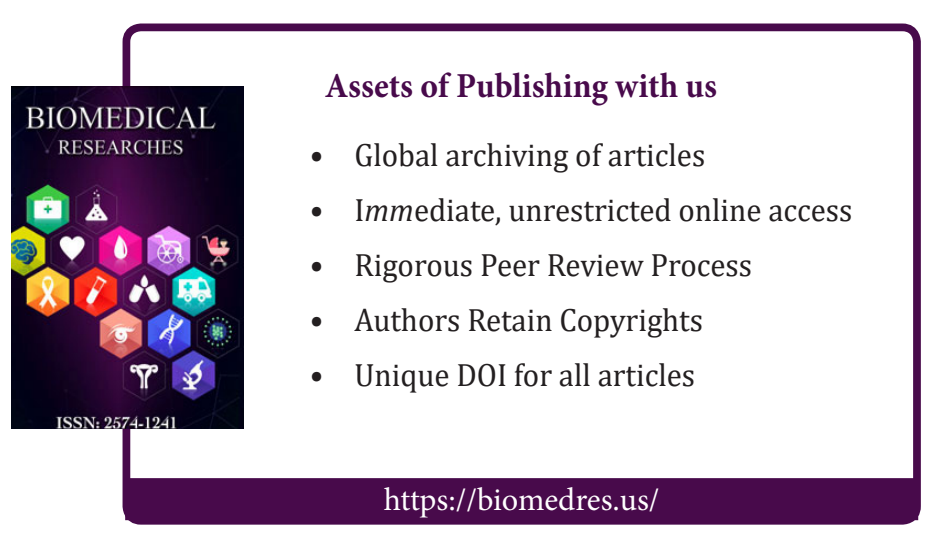

Cite this article: Yunfen W, Alfonso V B, Dhiraj R Jeyanandarajan. Can Pedicle Screws be Tested During Minimally Invasive Lumbosacral Fixation?. Biomed J Sci\&Tech Res 8(1)- 2018. BJSTR MS.ID.001596. DOI: 10.26717/ BJSTR.2018.08.001596. 